\title{
A Lab-Scale Membrane Reactor for the Generation of Anhydrous Diazomethane
}

\author{
Doris Dallinger, ${ }^{\dagger}$ Vagner D. Pinho, ${ }^{\dagger}$ Bernhard Gutmann, ${ }^{*, \ddagger}$ and C. Oliver Kappe ${ }^{*, \dagger}$ \\ ${ }^{\dagger}$ Institute of Chemistry, University of Graz, NAWI Graz, Heinrichstrasse 28, A-8010 Graz, Austria \\ ${ }^{\ddagger}$ Research Center Pharmaceutical Engineering GmbH (RCPE), Inffeldgasse 13, 8010 Graz, Austria
}

* Bernhard Gutmann. E-mail: bernhard.gutmann@uni-graz.at

* C. Oliver Kappe. E-mail: oliver.kappe@uni-graz.at.

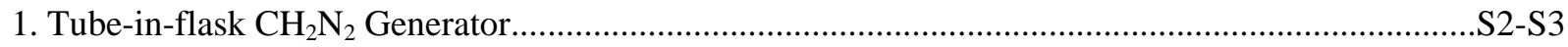

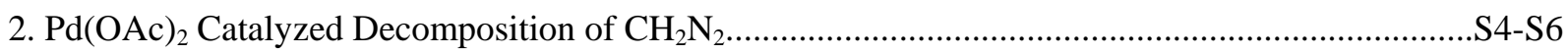

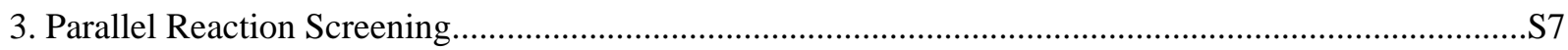

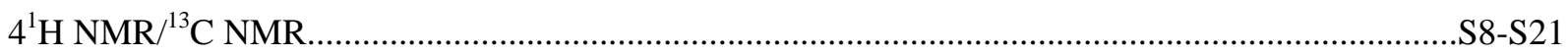




\section{Tube-in-flask $\mathrm{CH}_{2} \mathrm{~N}_{2}$ Generator}
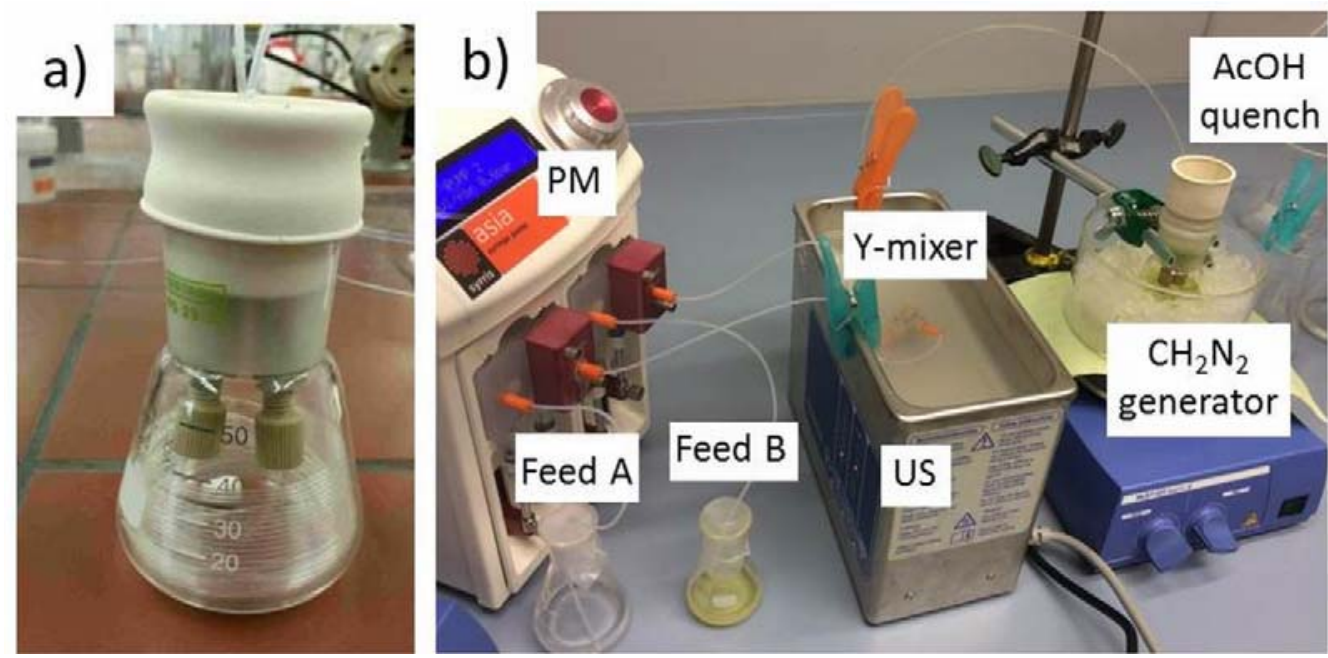

Figure S1. a) $\mathrm{CH}_{2} \mathrm{~N}_{2}$ Generator. b) Continuous flow set-up: feed A: $\mathrm{KOH}$ in $\mathrm{MeOH} / \mathrm{H}_{2} \mathrm{O}$; feed B: Diazald in DMF; PM: Asia syringe pump module; US: Ultrasonic bath with Y-mixer and inlet tubing (PFA, $1.59 \mathrm{~mm}$ o.d., $0.8 \mathrm{~mm}$ i.d.); $\mathrm{CH}_{2} \mathrm{~N}_{2}$ generator: $50 \mathrm{~mL}$ Erlenmeyer flask with $2.5 \mathrm{~mL}$ AF-2400 tubing; outlet tubing into AcOH quench. It should be noted that the tubing inside the flask should be sufficiently covered with solvent.

Cleaning of the reactor: The $\mathrm{CH}_{2} \mathrm{~N}_{2}$ generator can easily be cleaned by rinsing with an appropriate solvent, e.g. acetone or diethyl ether. If Pd black precipitates, the reactor should be rinsed with nitric acid. Since nitric acid reacts violently with organic solvents, care has to be taken, that the reactor is free from acetone, THF or diethyl ether. After the nitric acid wash, the reactor should be rinsed with water, then with acetone and diethyl ether. 


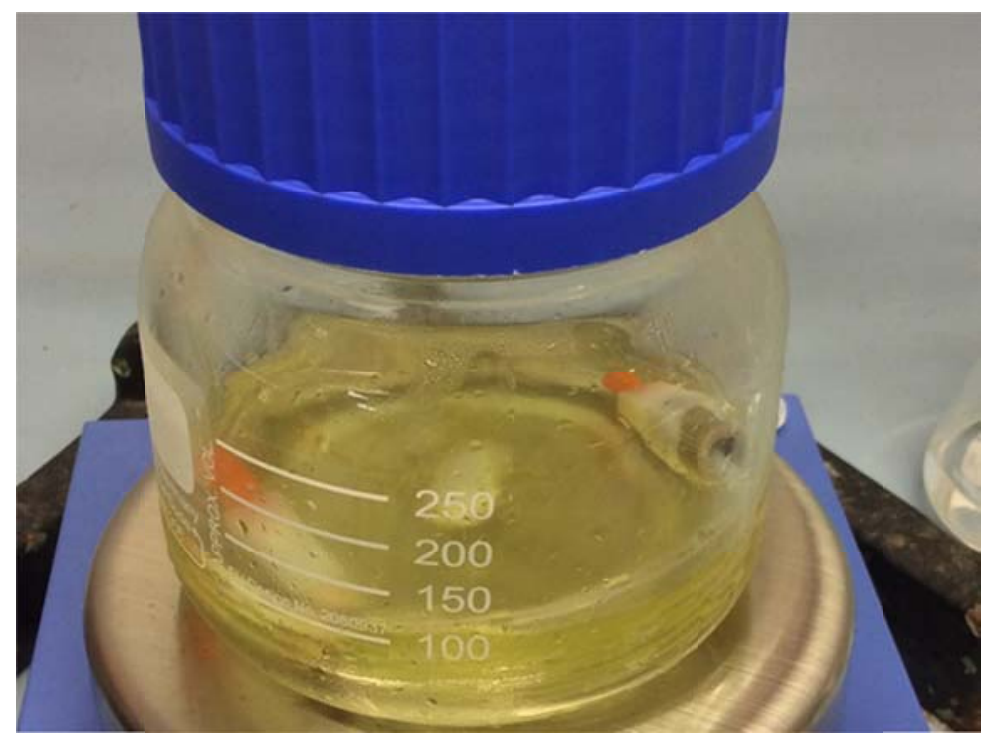

Figure S2. $\mathrm{CH}_{2} \mathrm{~N}_{2}$ Generator with one AF-2400 tubing $(1.55 \mathrm{~mm}$ i.d., $1.5 \mathrm{~m}$ length, $2.8 \mathrm{~mL}$ residence volume) that was wrapped into a $250 \mathrm{~mL}$ Duran flask. The flask was filled with 100 $\mathrm{mL} \mathrm{Et}_{2} \mathrm{O}$ to cover the tubing with solvent.

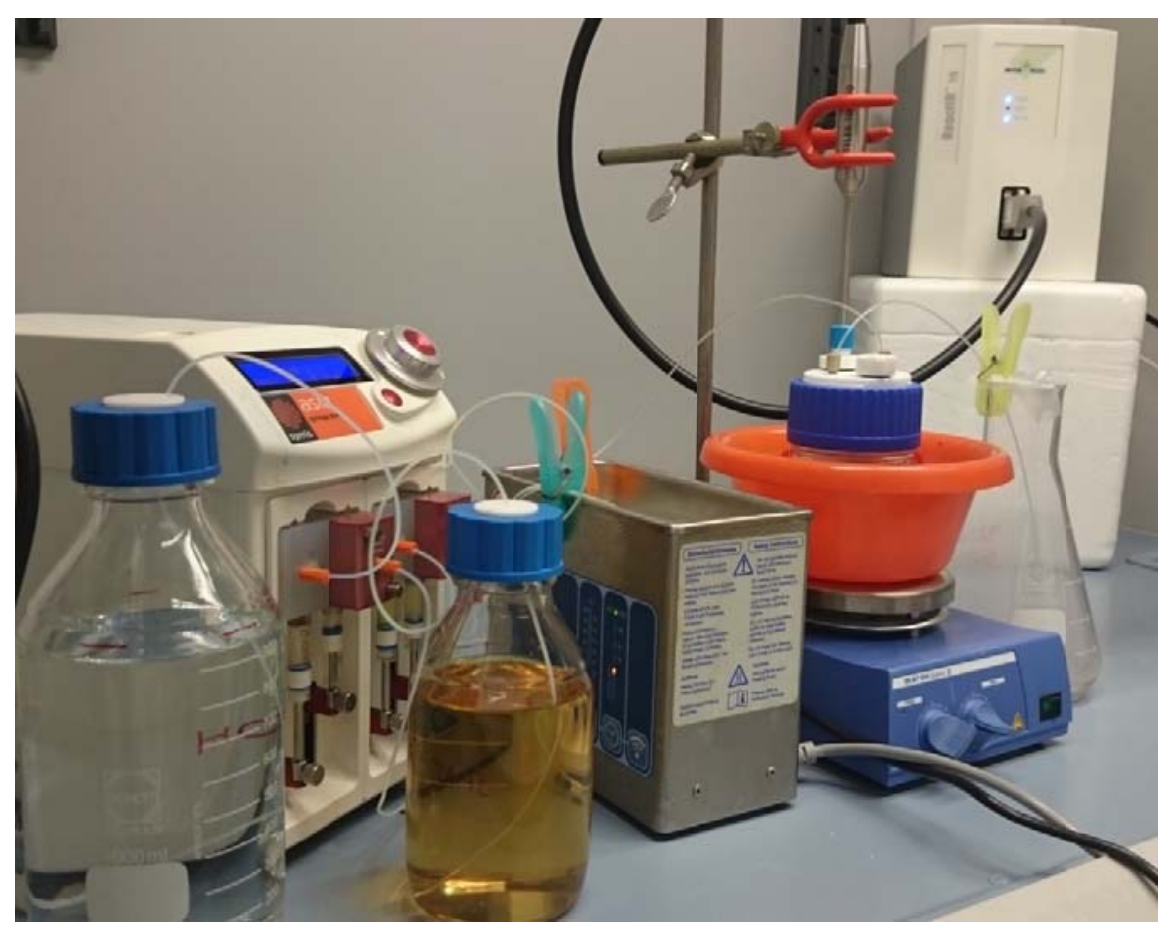

Figure S3. Continuous flow set-up using the ReactIR instrument. 


\section{2. $\mathrm{Pd}(\mathrm{OAc})_{2}$ Catalyzed Decomposition of $\mathrm{CH}_{2} \mathrm{~N}_{2}$}

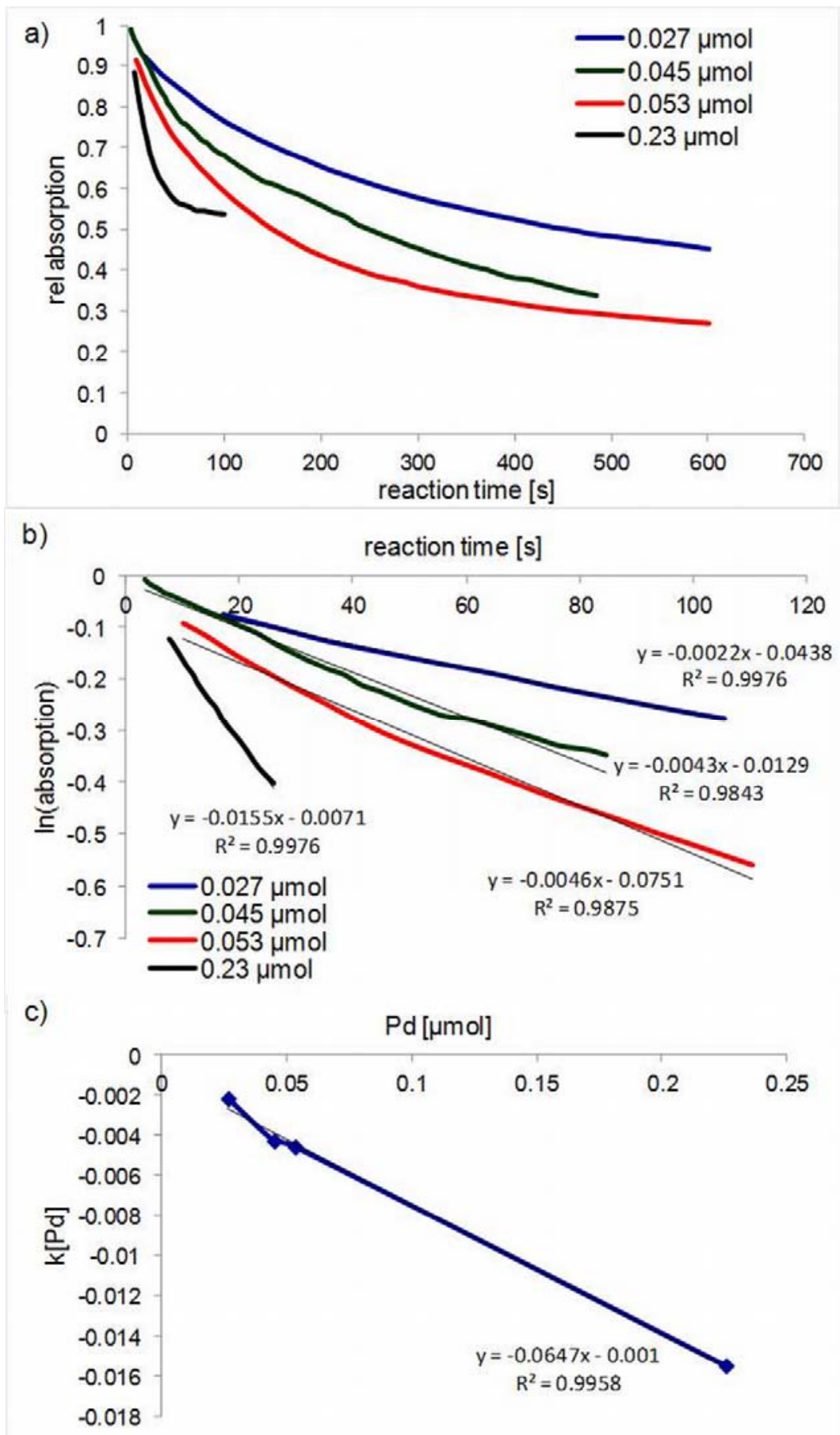

Figure S4. a) Decomposition of $\mathrm{CH}_{2} \mathrm{~N}_{2}$ in THF as solvent ( $1 \mathrm{~mL}$ of a $\sim 0.18 \mathrm{M}$ solution) in the presence of various amounts of $\mathrm{Pd}(\mathrm{OAc})_{2}$ (monitored by UV/Vis spectroscopy at $410 \mathrm{~nm}$ ). b) The initial decomposition rate follows a first order rate law, but the reaction rate then decreases. c) The initial decomposition rate is roughly proportional to the $\mathrm{Pd}(\mathrm{OAc})_{2}$ concentration. 


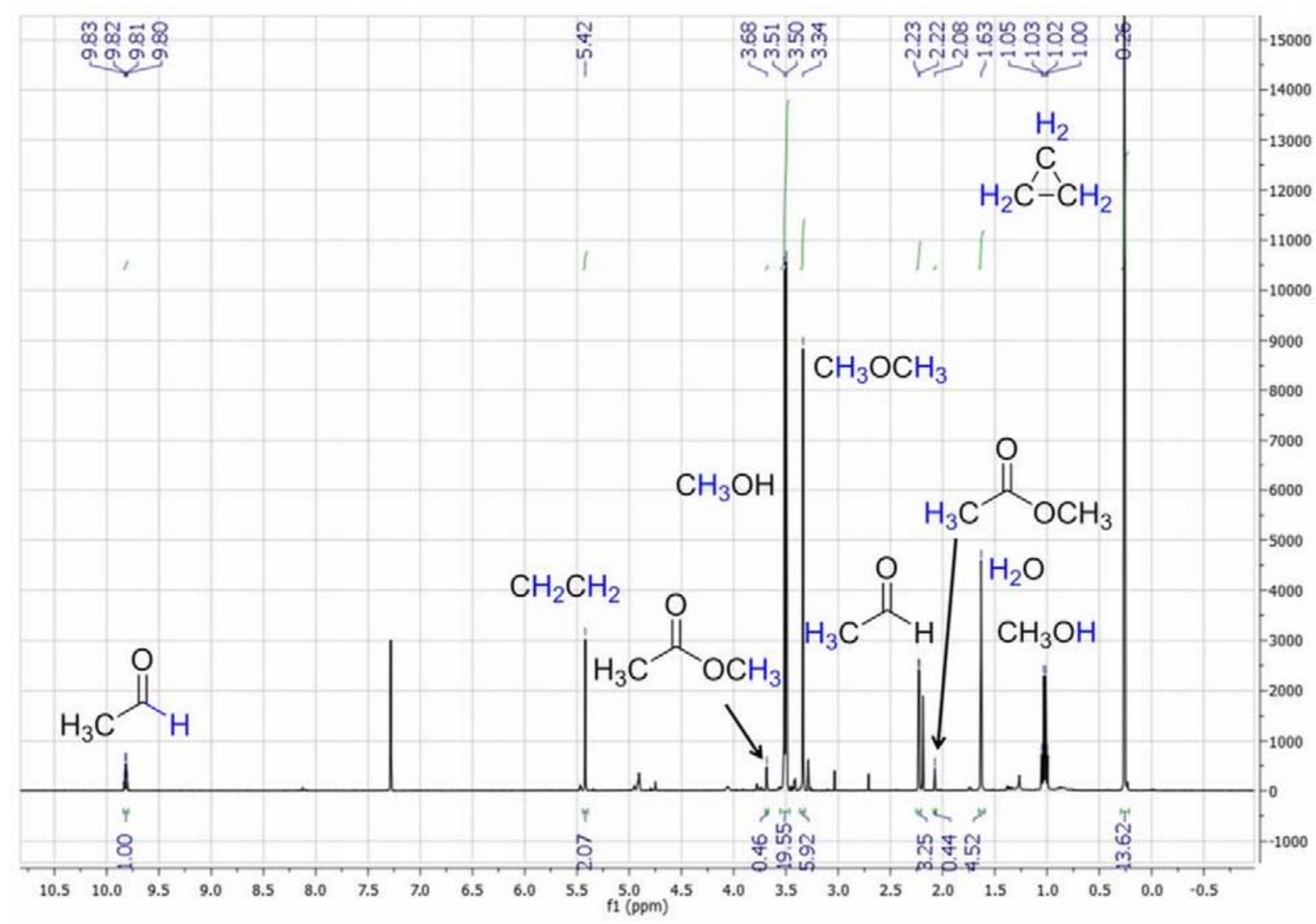

Figure S5. Tentative assignment of the products of the $\mathrm{Pd}(\mathrm{OAc})_{2}$ catalyzed decomposition of $\mathrm{CH}_{2} \mathrm{~N}_{2}$ in $\mathrm{CDCl}_{3}\left(0.025 \mathrm{~mol} \% \mathrm{Pd}(\mathrm{OAc})_{2}\right.$ with respect to $\left.\mathrm{CH}_{2} \mathrm{~N}_{2}\right)$. For these experiments, a $\mathrm{CH}_{2} \mathrm{~N}_{2}$ solution in $\mathrm{CDCl}_{3}$ was prepared as described above. $0.7 \mathrm{~mL}$ of the solution was transferred to a NMR tube. $\mathrm{Pd}(\mathrm{OAc})_{2}$ (from a stock solution in $\mathrm{CDCl}_{3}$ ) was added in one shot, the tube closed and immediately analyzed. 

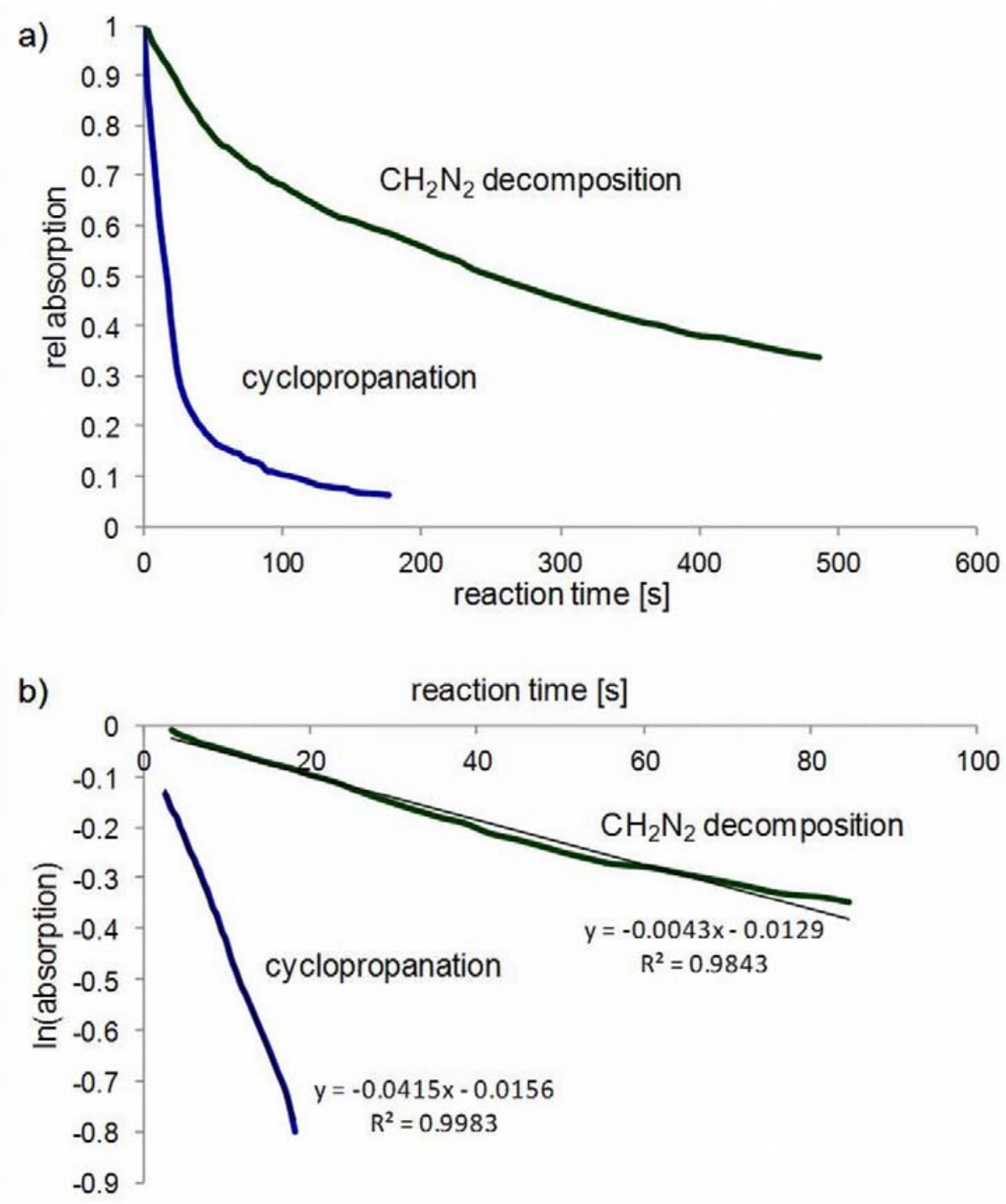

Figure S6. a) Comparison of the disappearance of UV/Vis absorption (410 nm) of the $\mathrm{CH}_{2} \mathrm{~N}_{2}$ solution in the presence of $0.045 \mu \mathrm{mol} \mathrm{Pd}(\mathrm{OAc})_{2}$ and in the presence of styrene $(0.2$ $\mathrm{mmol}) / \mathrm{Pd}(\mathrm{OAc})_{2}(0.045 \mu \mathrm{mol} ; 0.022 \mathrm{~mol} \%)$ in THF as solvent $(1 \mathrm{~mL}$ of a $\sim 0.18 \mathrm{M}$ solution of $\mathrm{CH}_{2} \mathrm{~N}_{2}$ ). b) The initial reaction rate for the cyclopropanation reaction is one order of magnitude larger than for $\mathrm{CH}_{2} \mathrm{~N}_{2}$ decomposition. 


\section{Parallel Reaction Screening}

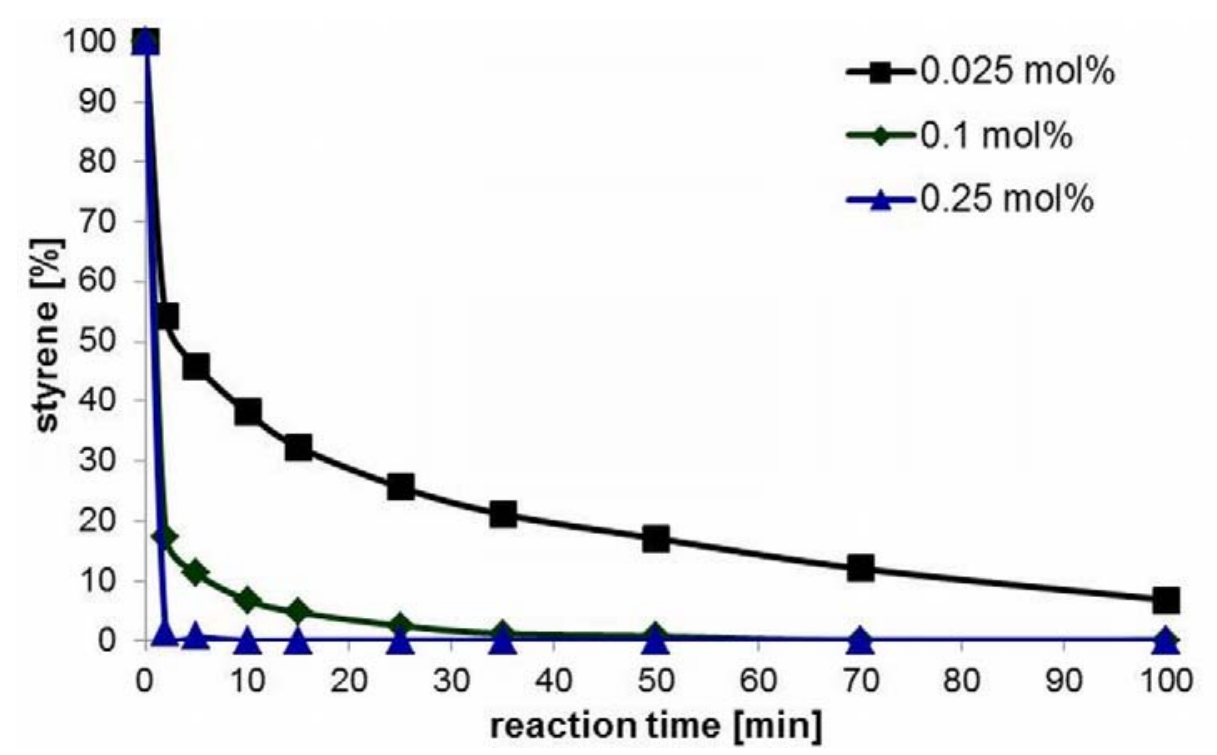

Figure S7. Reaction rate of cyclopropanation with different catalyst loadings for styrene $\left(\mathrm{Pd}(\mathrm{OAc})_{2}, 0.2 \mathrm{mmol}\right.$ of styrene, 2 equivalents of $\mathrm{CH}_{2} \mathrm{~N}_{2}$ in THF as solvent; analyzed by GC-MS). $\mathrm{CH}_{2} \mathrm{~N}_{2}$ was pipetted rapidly to a mixture of styrene and catalyst.

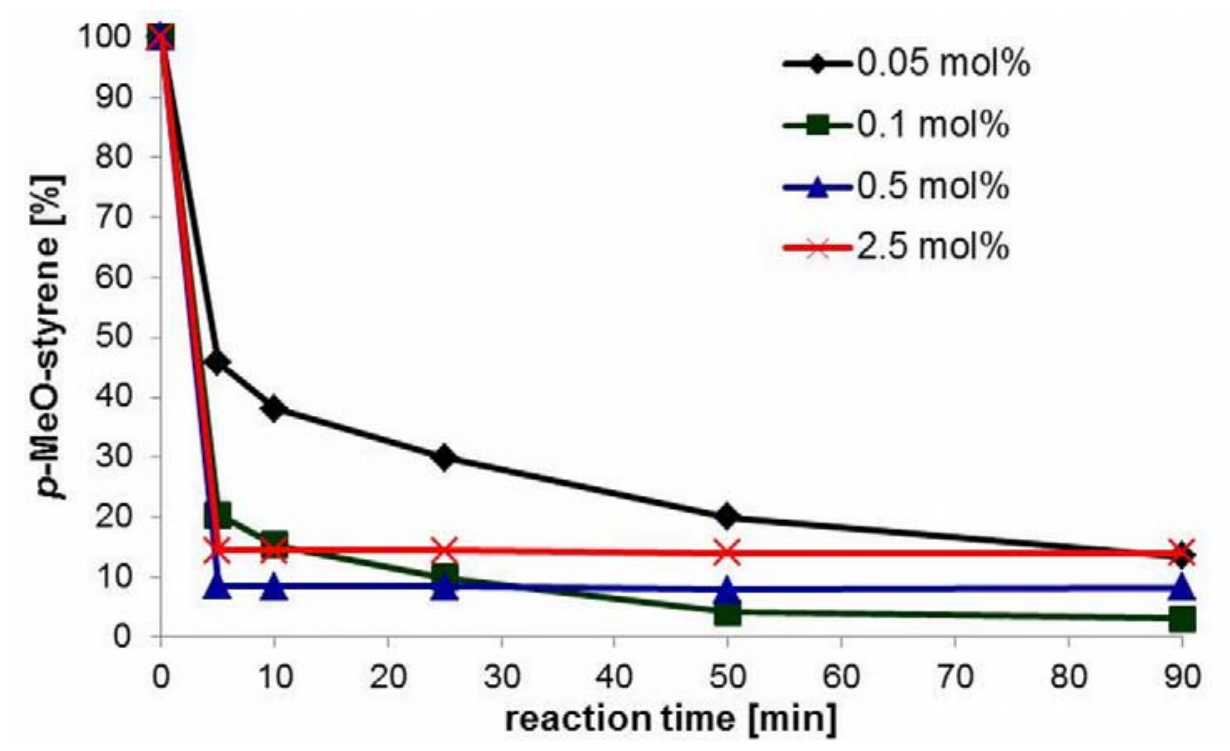

Figure S8. Reaction rate of cyclopropanation with different catalyst loadings for $p$-MeO-styrene (0.2 mmol of $p$-MeO-styrene, 2 equivalents of $\mathrm{CH}_{2} \mathrm{~N}_{2}$ in THF as solvent; analyzed by GC-MS). $\mathrm{Pd}(\mathrm{OAc})_{2}$ was pipetted to the reaction a mixture of $p-\mathrm{MeO}$-styrene and $\mathrm{CH}_{2} \mathrm{~N}_{2}$. Reactions with low catalyst loadings proceeded slower, but ultimately provided higher conversions. 
4. ${ }^{1} \mathrm{H}$ NMR (300 MHz) $/{ }^{13} \mathrm{C}$ NMR (75 MHz) in $\mathrm{CDCl}_{3}$
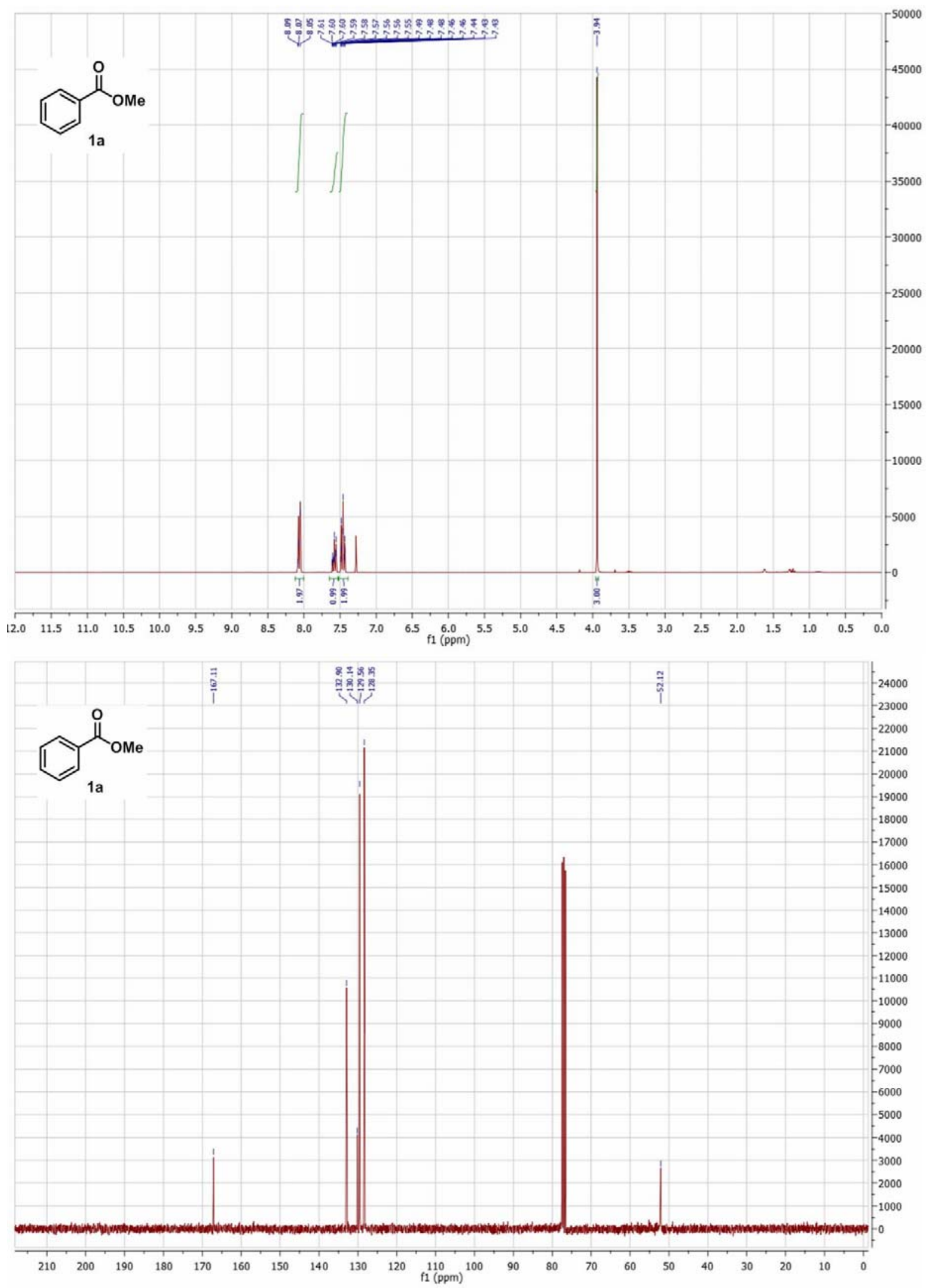

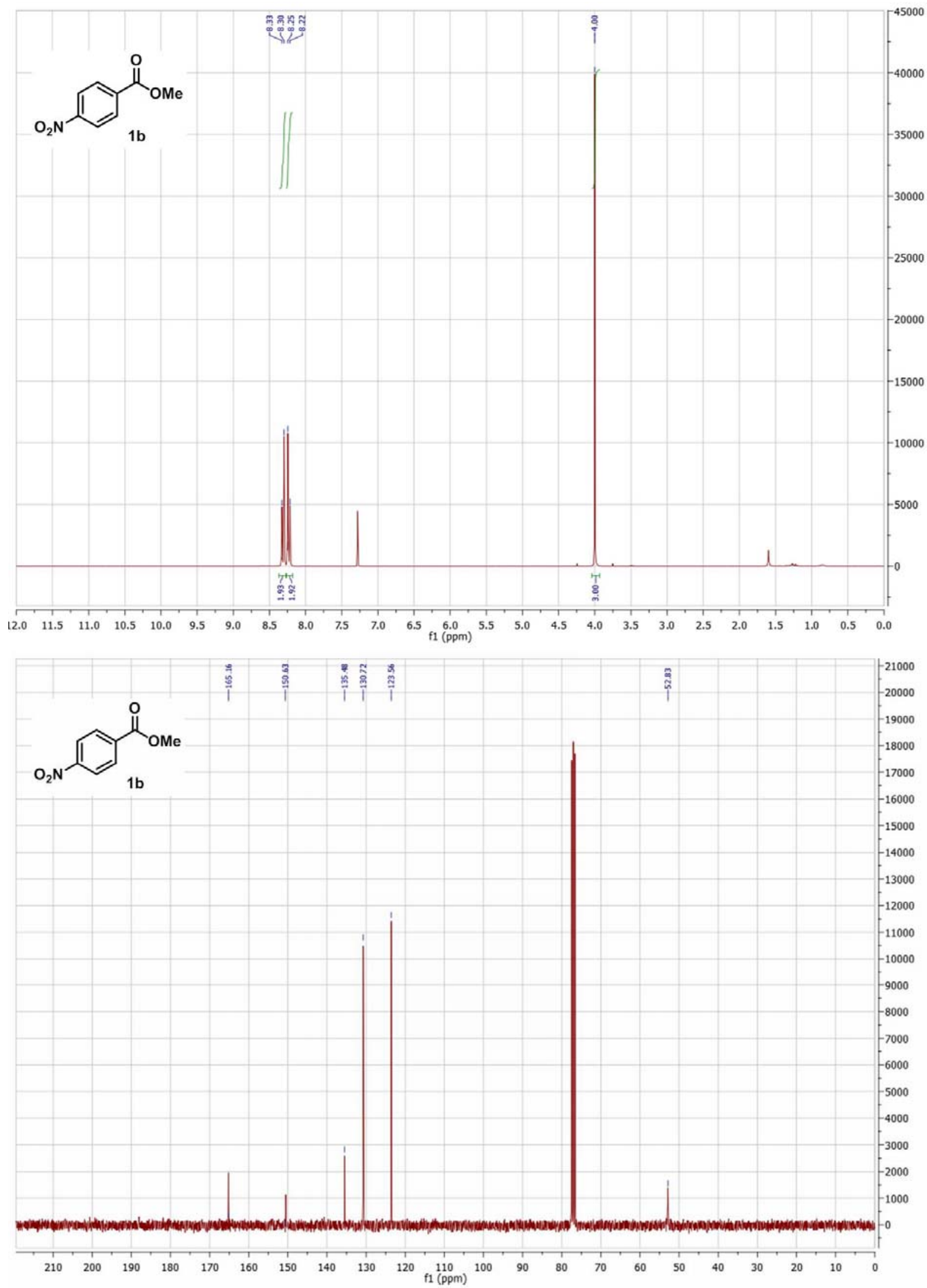

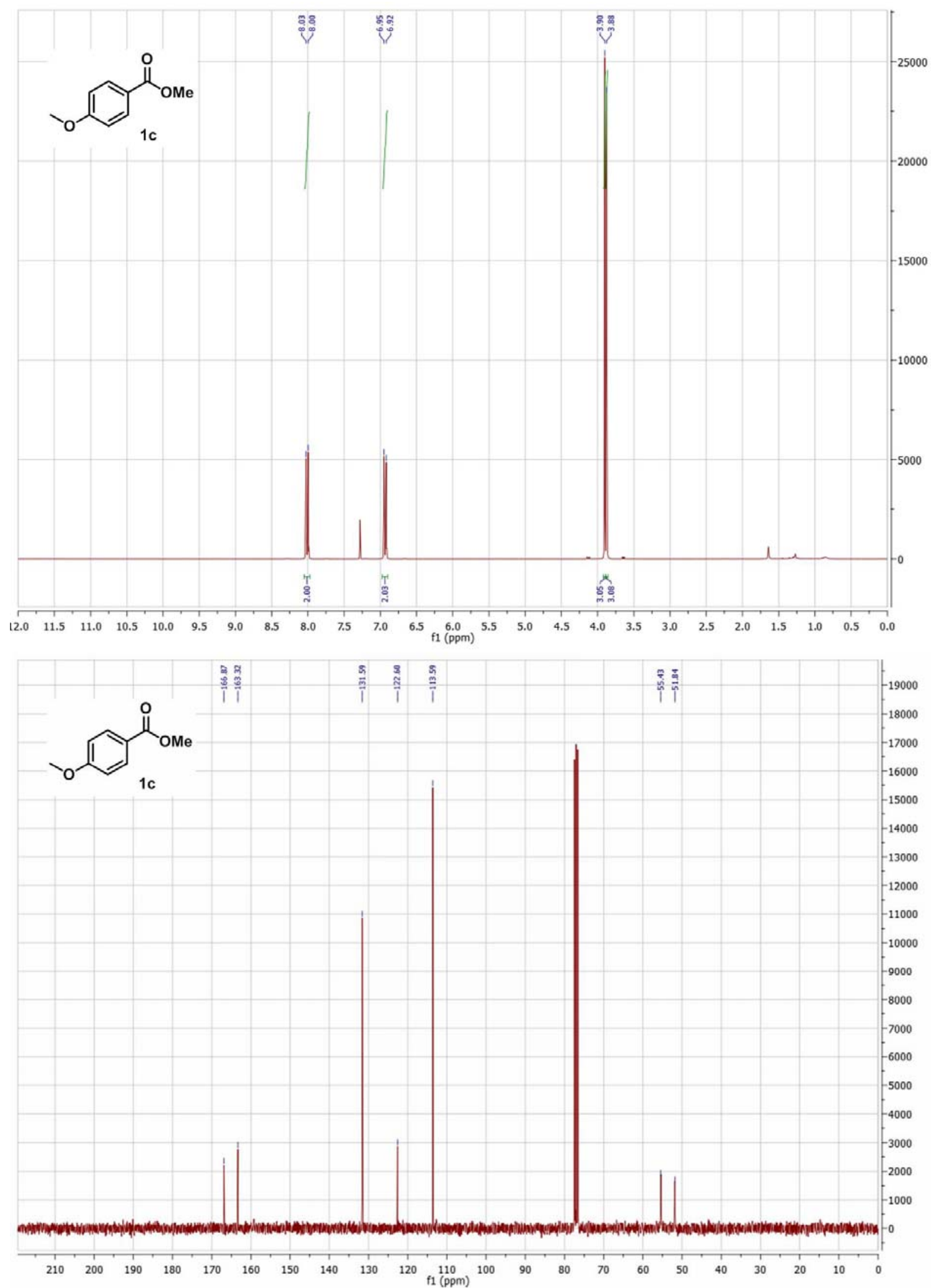


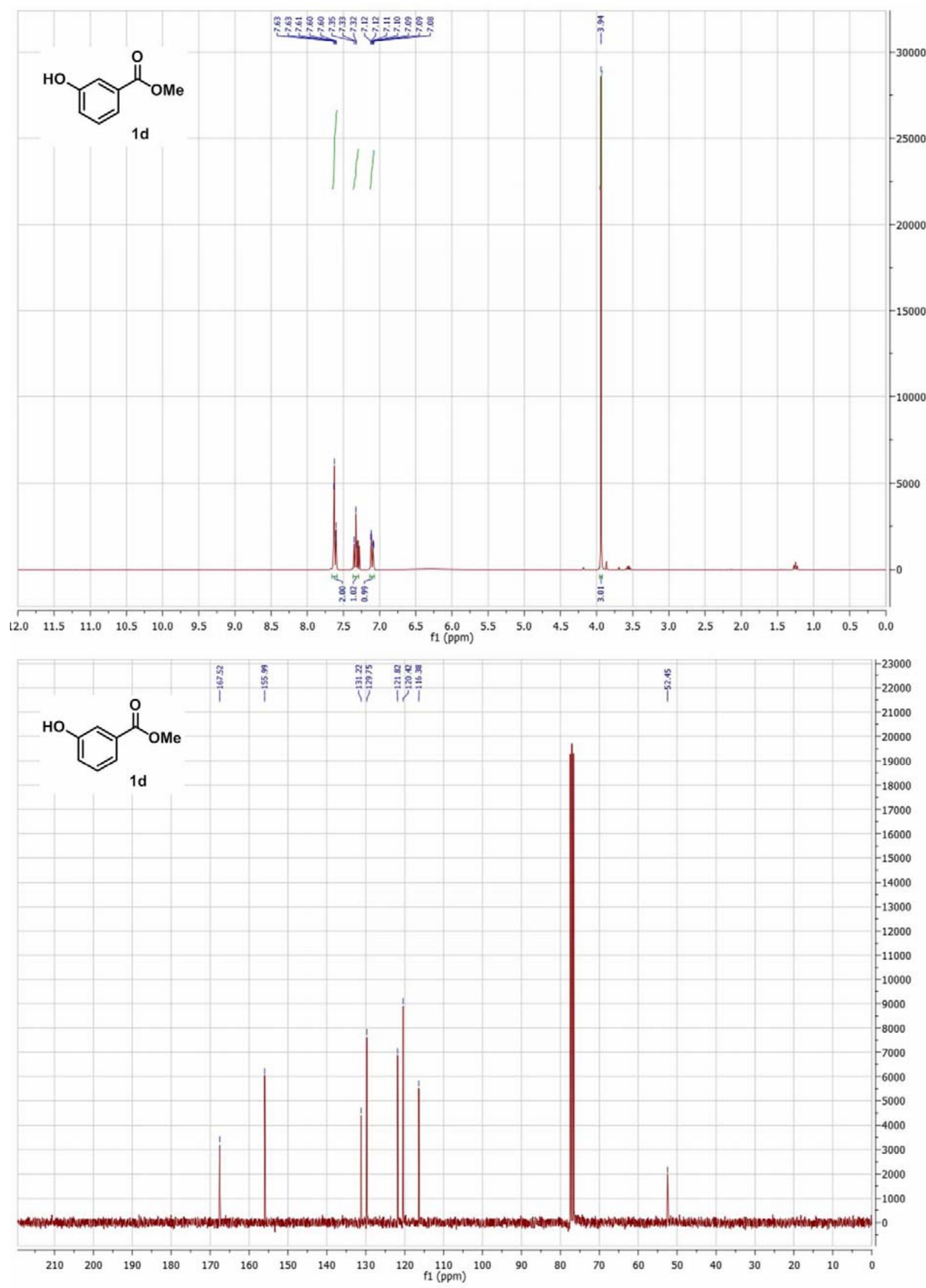



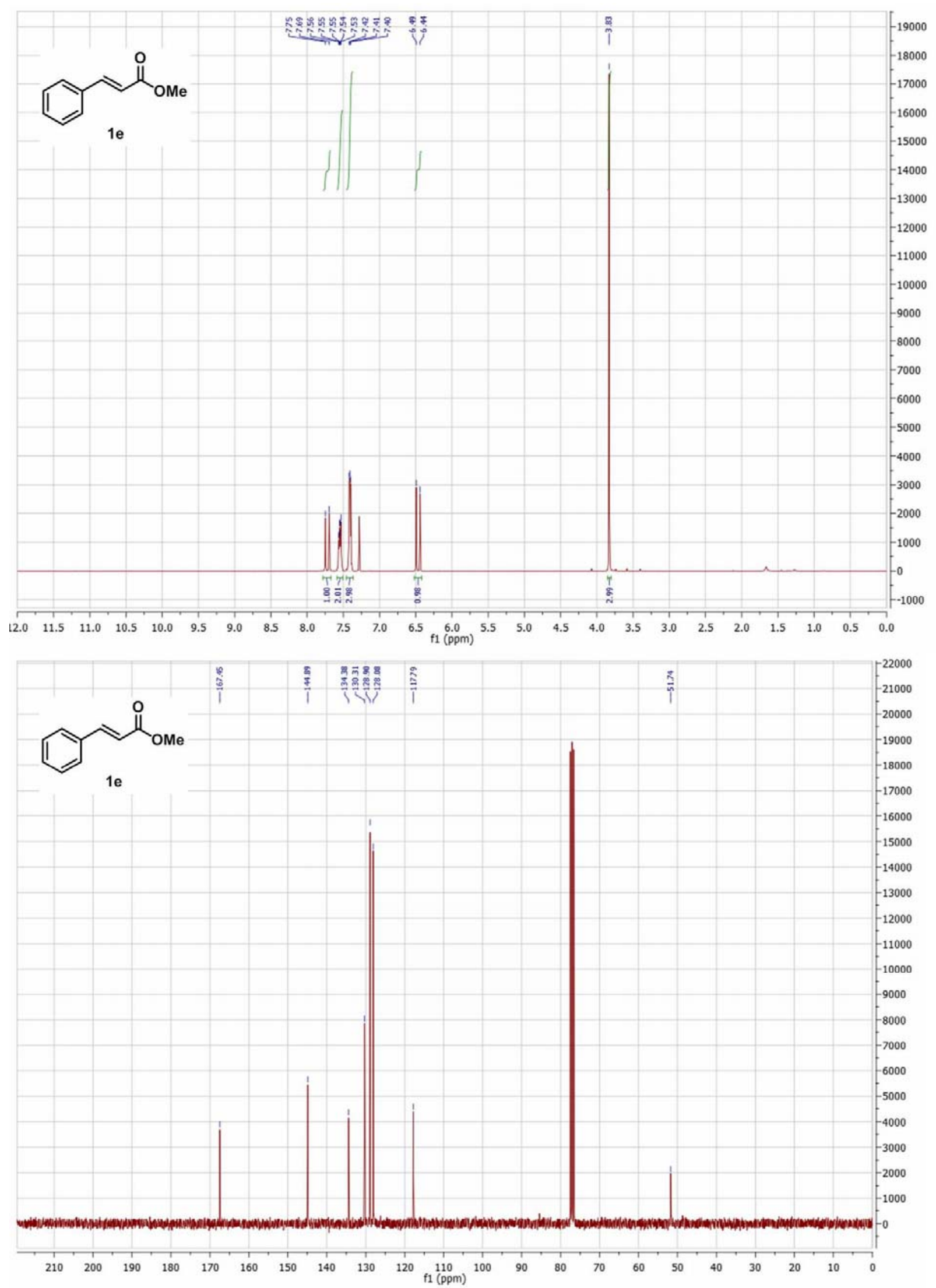

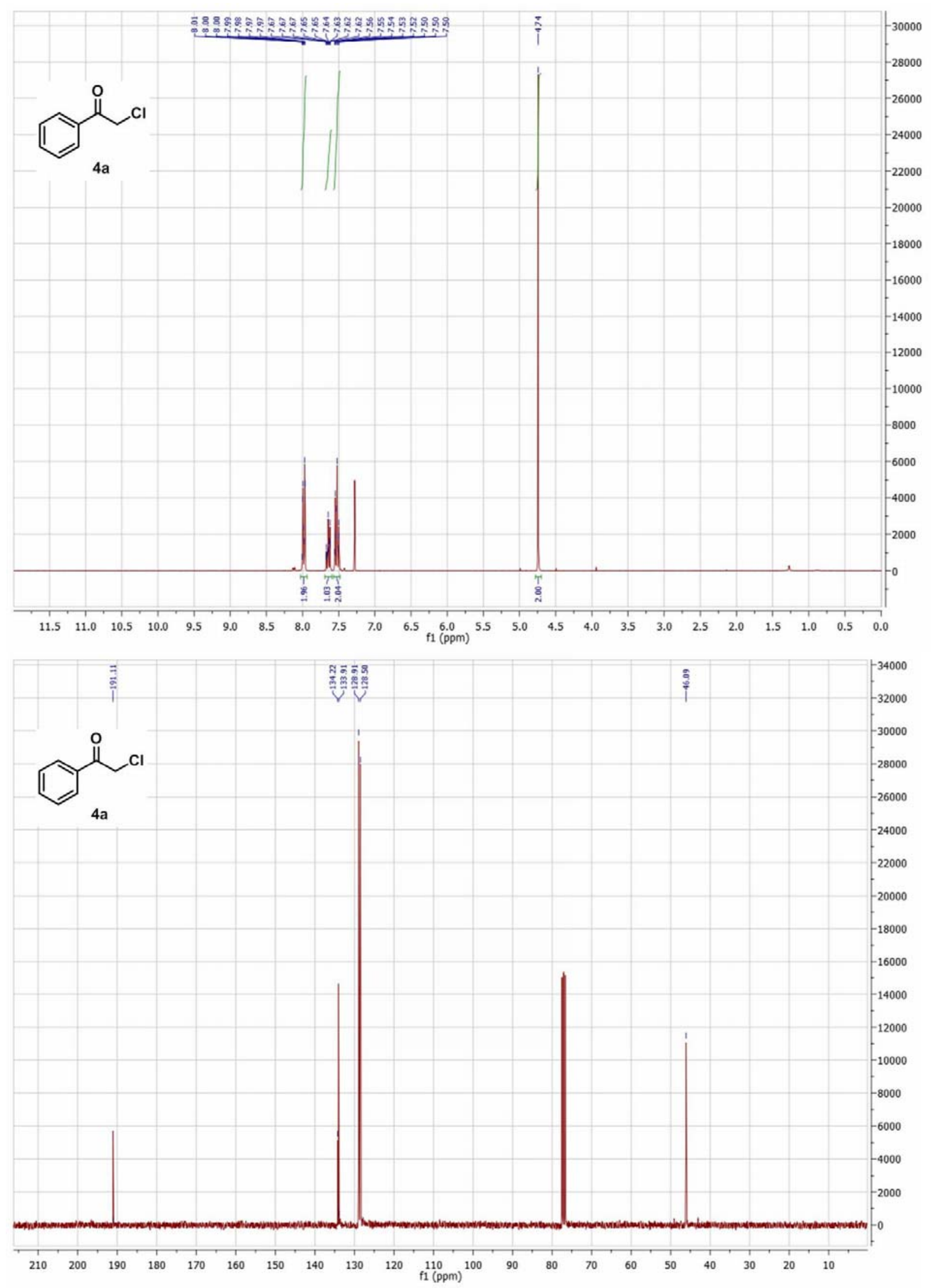

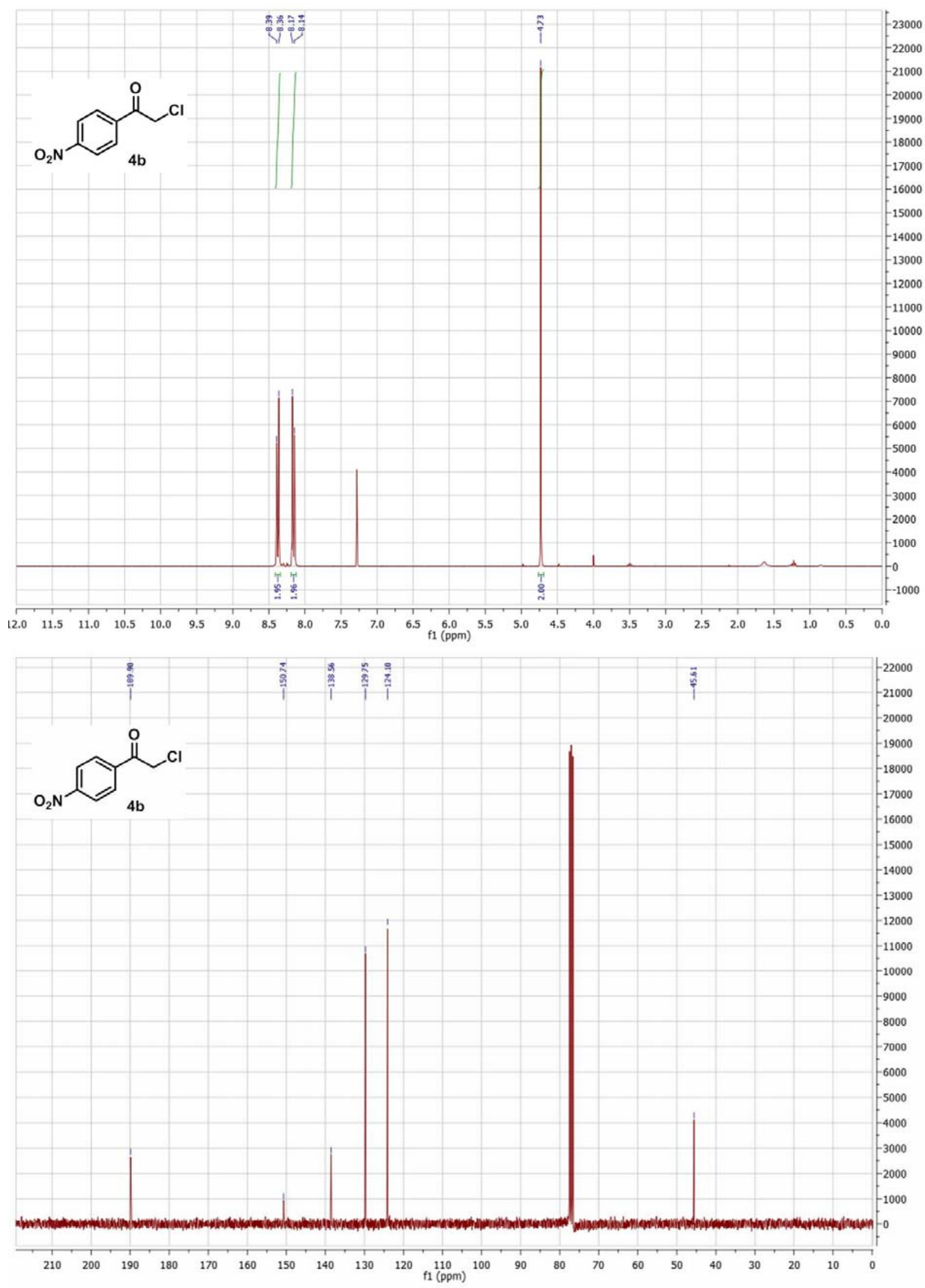

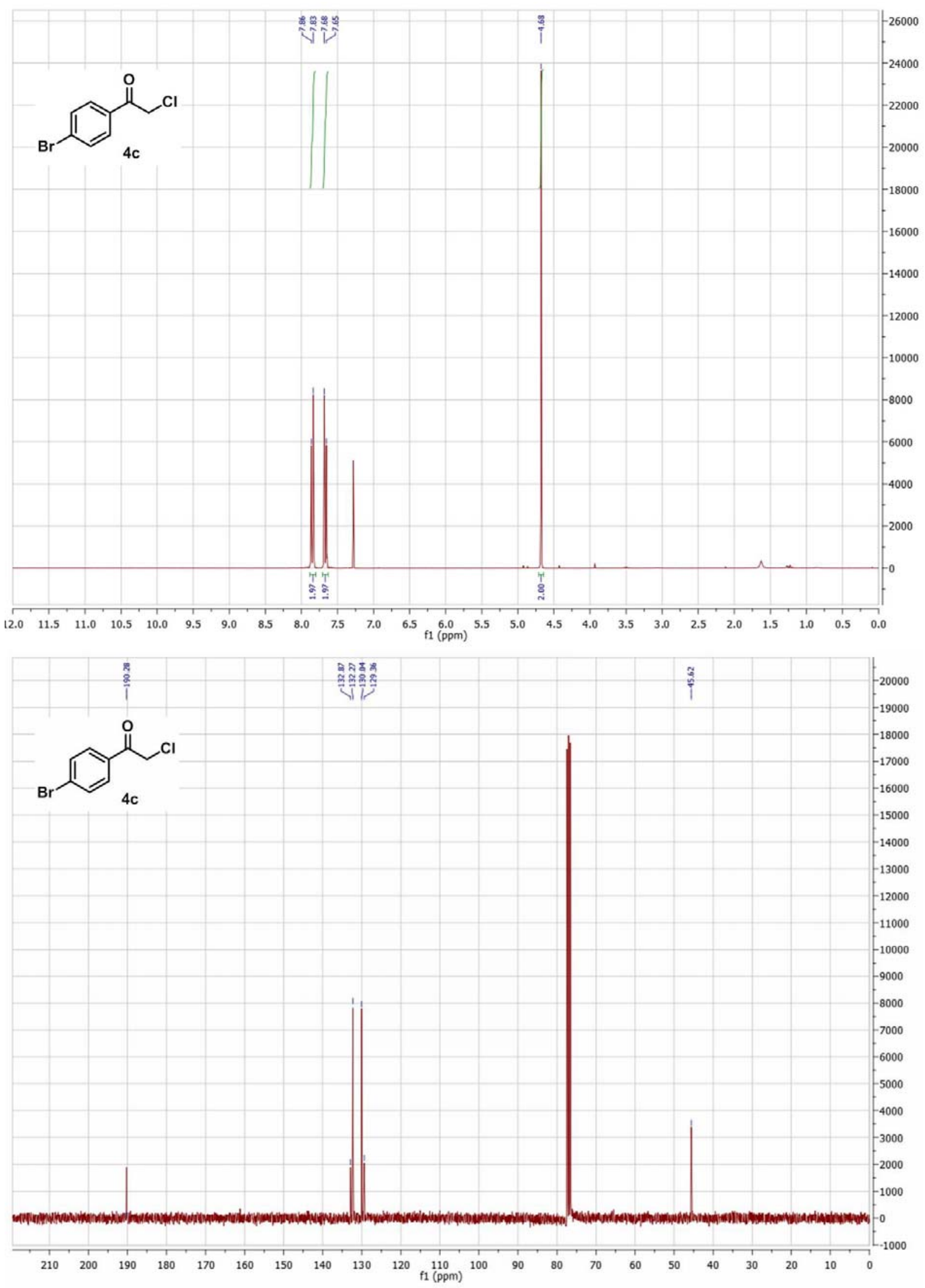

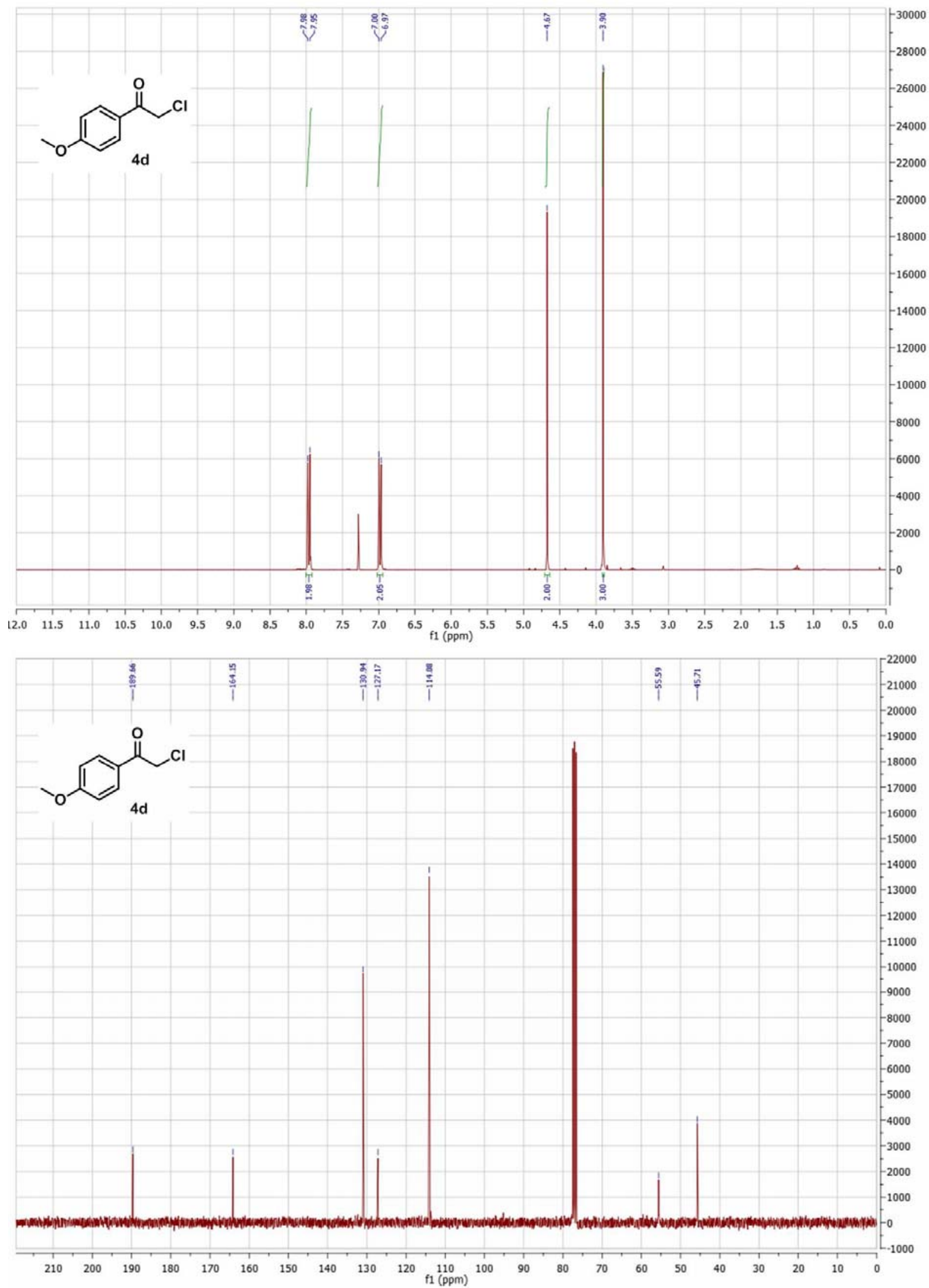

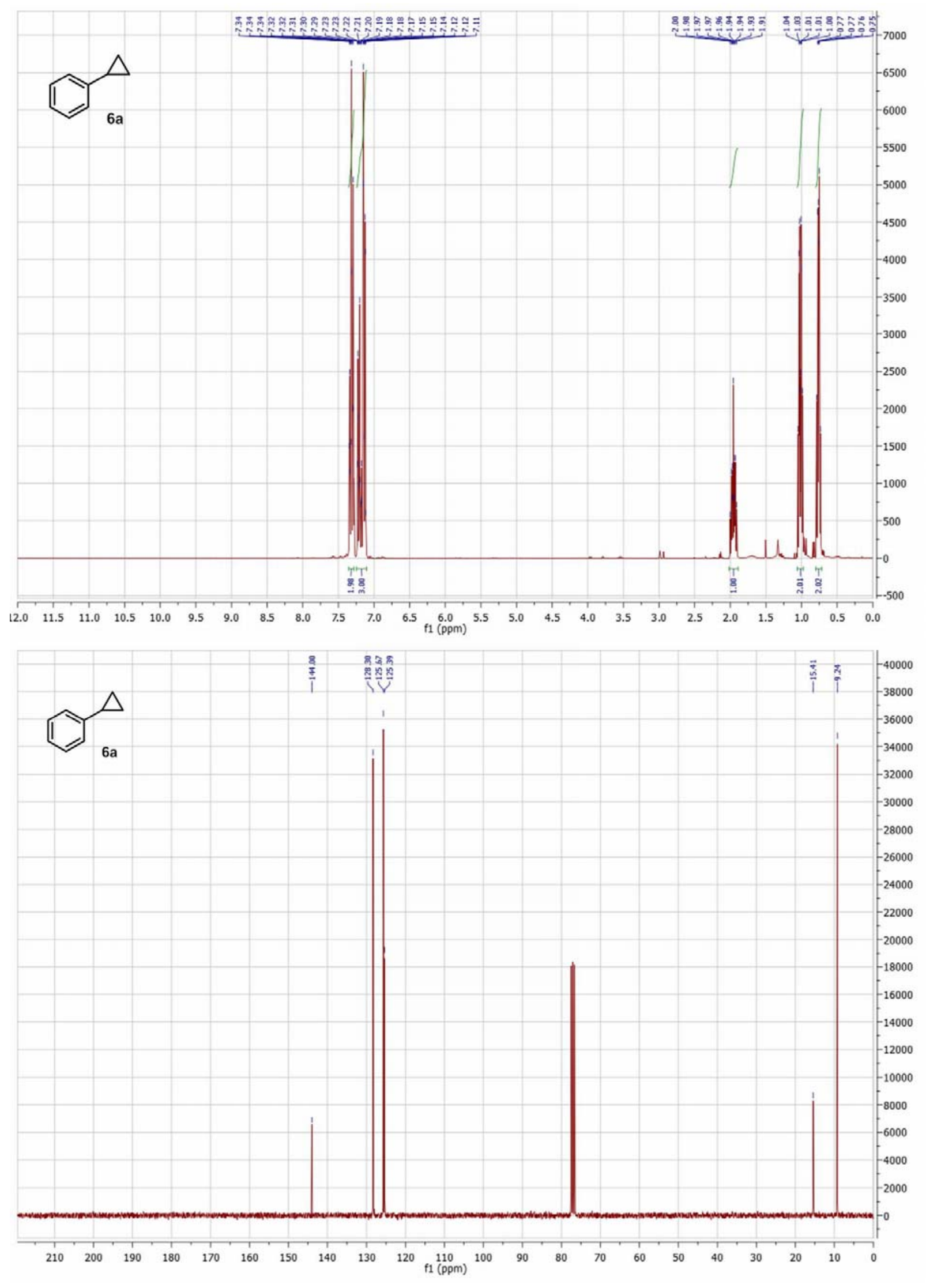

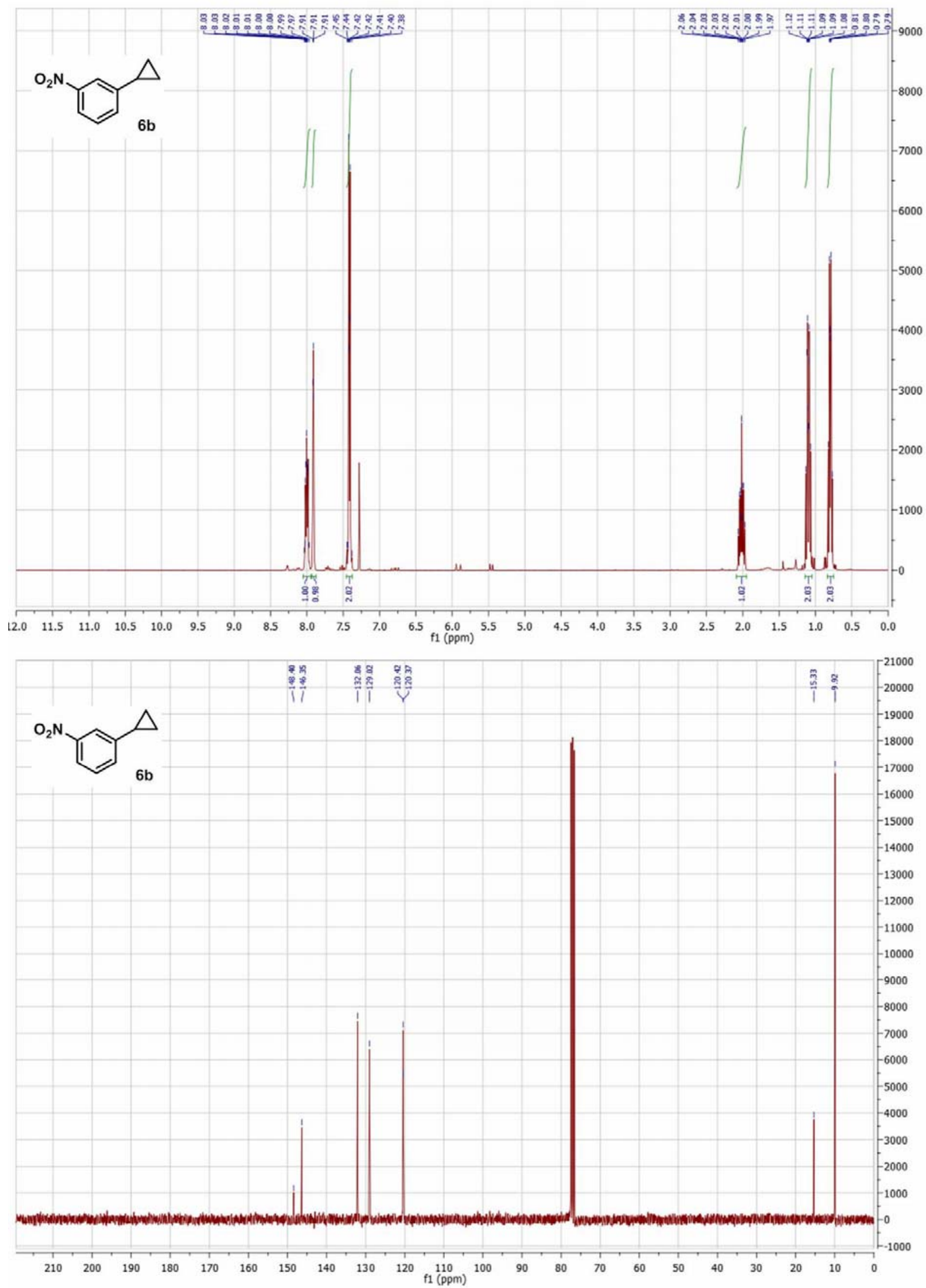

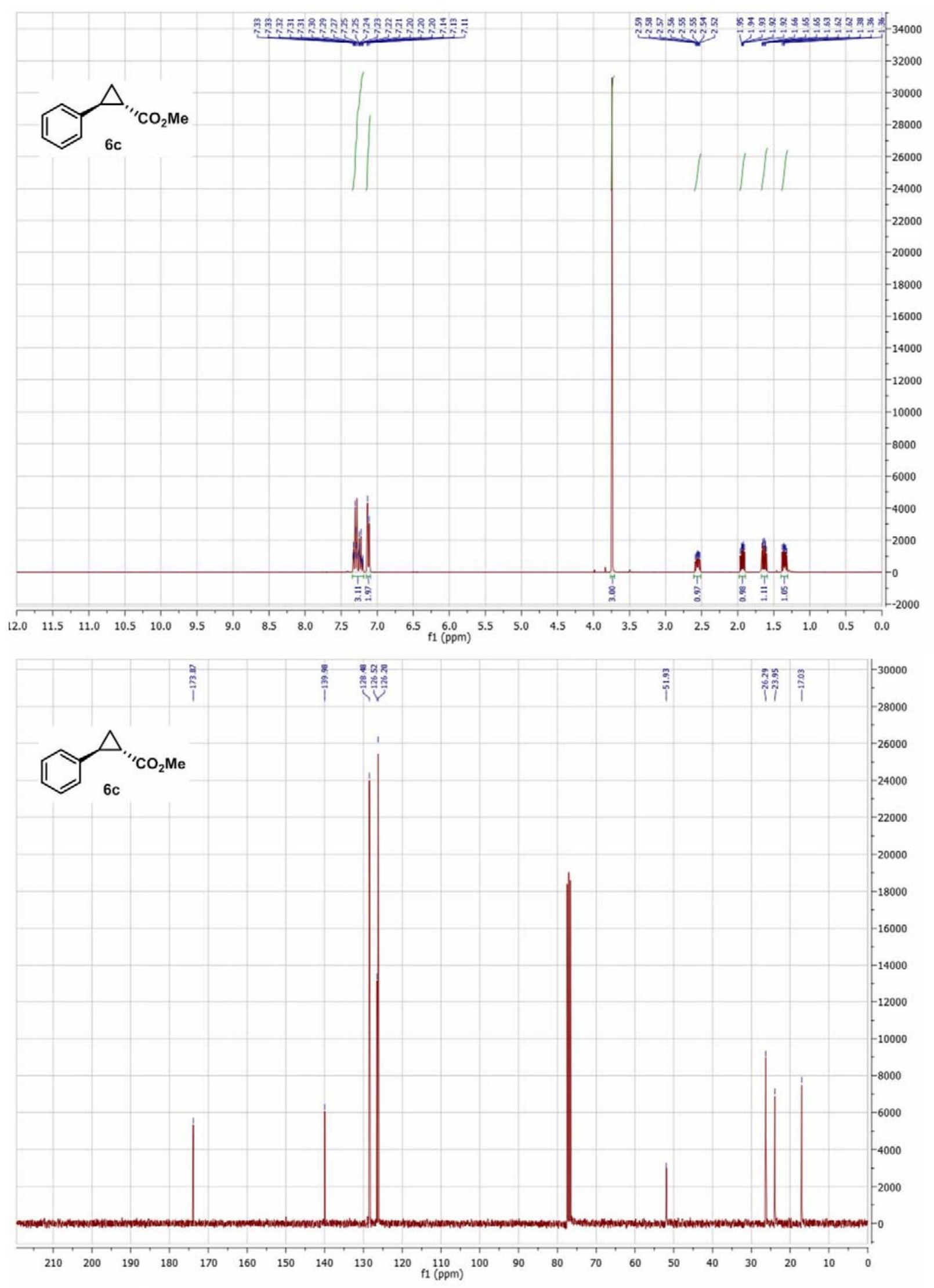

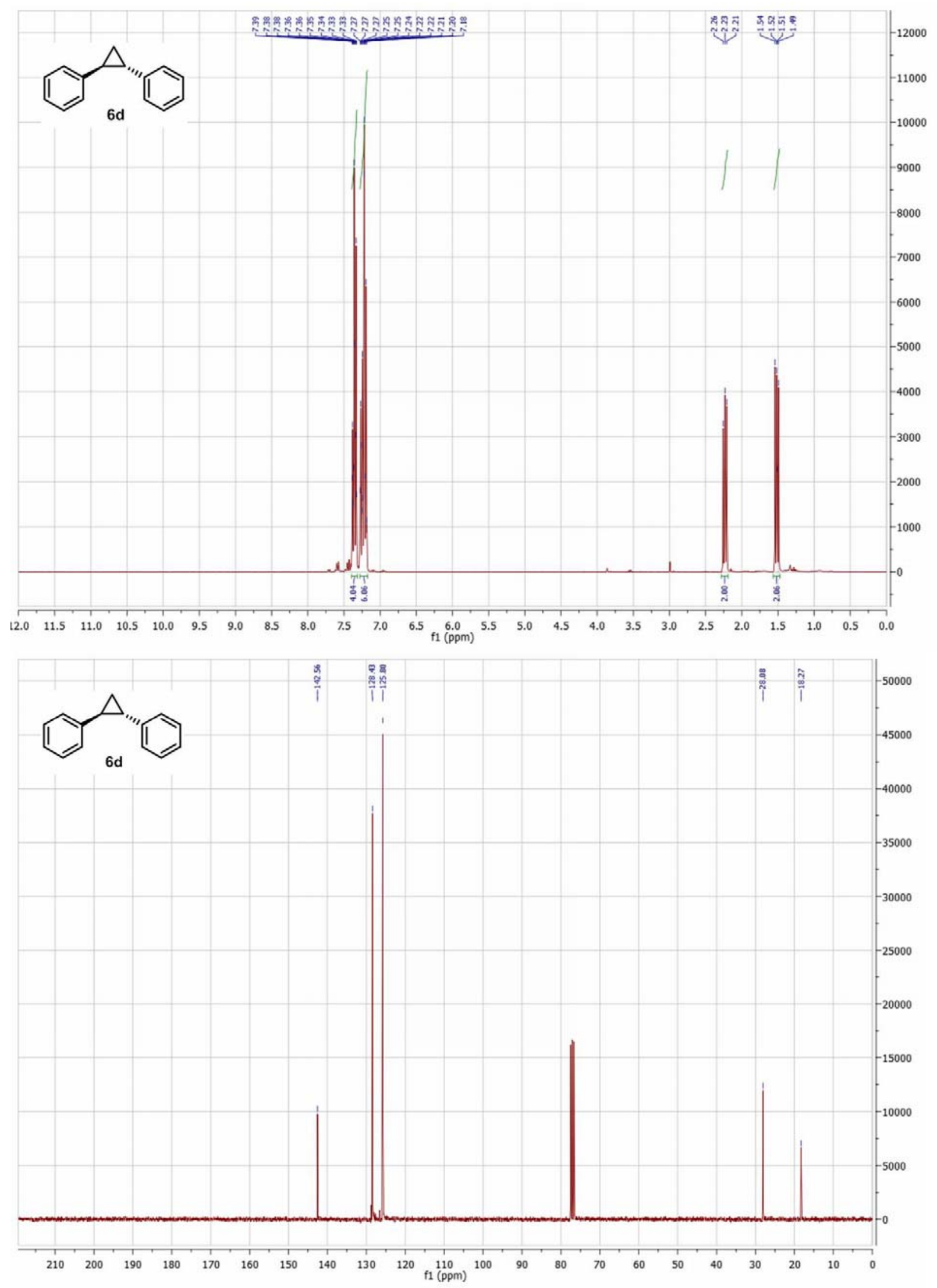

S20 

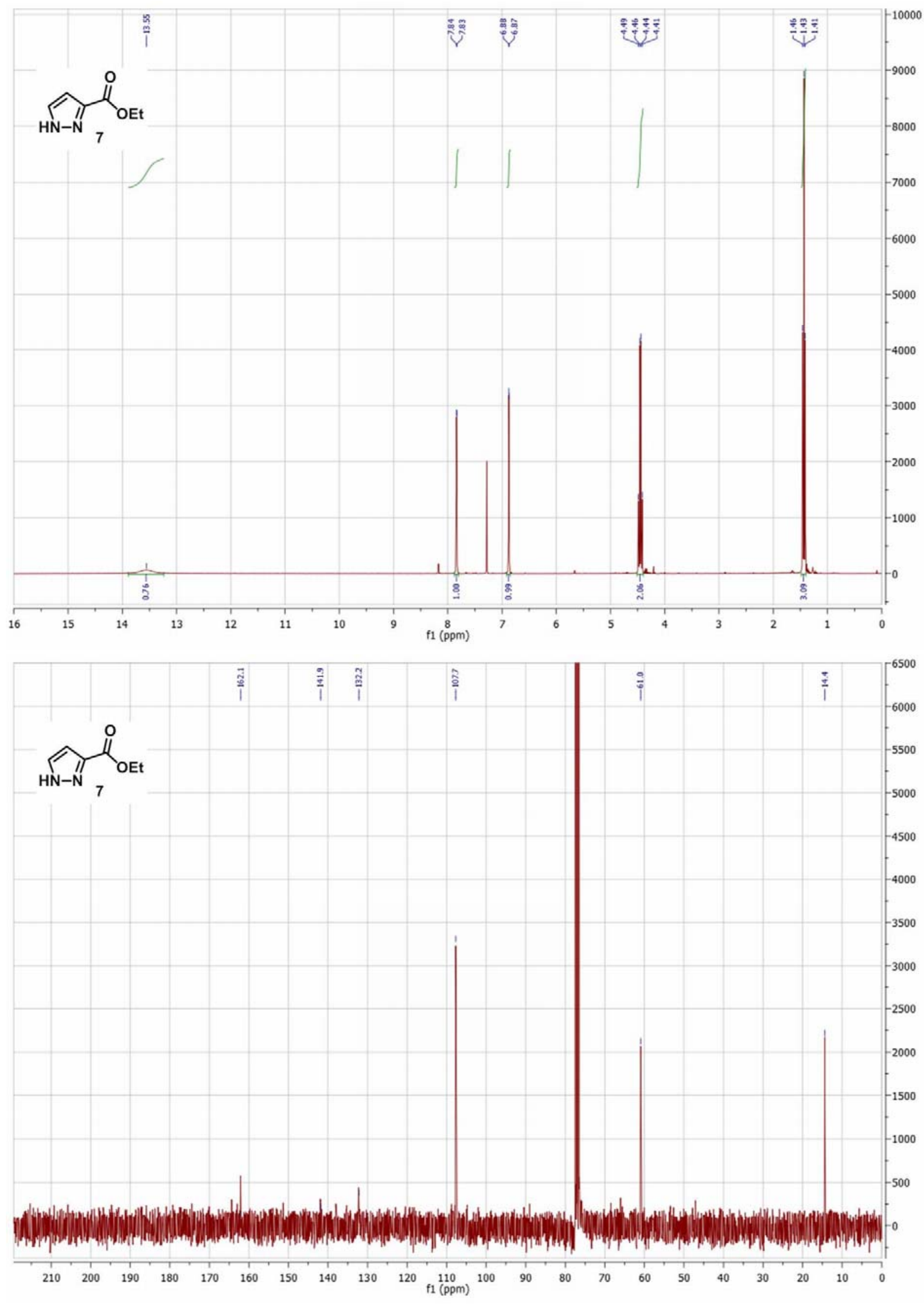